\title{
Garanticemos la calidad de las muestras respiratorias para diagnosticar COVID-19
}

Let's guarantee the quality of respiratory samples to diagnose COVID-19

Marcela Gómez-Garzón - MSc ${ }^{1}$, Martha Patricia Isaza-Cortes², Catalina Ibañez-Galvis ${ }^{3}$

\section{Resumen}

Este artículo y video disponibles en el OJS de la Revista describe los procedimientos para la recolección de hisopos respiratorios que garantizan la bioseguridad y el diagnóstico de COVID-19 en adultos y niños.

Palabras claves: infecciones por coronavirus, manejo de especímenes.

\section{Abstract}

This article and video describes the procedures for the collection of respiratory swabs that guarantee biosecurity and the diagnosis of COVID-19 in adults and children.

Keywords: Coronavirus Infections, Specimen Handling.

1. Profesor titular, Fundación Universitaria de Ciencias de la Salud (FUCS).

ORCID: https://orcid.org/0000-0003-0584-8783

2. Instructor asociado, Fundación Universitaria de Ciencias de la Salud (FUCS).

ORCID: https://orcid.org/0000-0002-6768-8271

3. Pasante, Fundación Universitaria de Ciencias de la Salud (FUCS).

ORCID: https://orcid.org/0000-0001-9412-970X

Correo electrónico de correspondencia: mgomez@fucsalud.edu.co

https://doi.org/10.22490/24629448.4192 


\section{Introducción}

La recolección adecuada de las muestras respiratorias es un paso sensible de la fase preanalítica en el diagnóstico de laboratorio de COVID-19 (1). Aunque son mínimas las contraindicaciones para la toma de la muestra, debe conocerse las variantes anatómicas, como desviación del tabique o fosas nasales bloqueadas, para obtener las muestras adecuadas (2). El $30 \%$ de los hisopados de pacientes clínicamente sintomáticos de COVID-19 dan un falso positivo y en poblaciones asintomáticas esta tasa es más alta (3). La cinética de la carga viral (ARN viral) es diferente en cada etapa de la enfermedad, su punto máximo es 4-6 días después del inicio de los síntomas y está directamente relacionado con la positividad de las pruebas $(2,4,5)$.

La OMS y el CDC publicó las recomendaciones mundiales para la orientación al público y a los profesionales de la salud sobre el nuevo coronavirus (2019-nCOV) $(6,7)$; en Colombia, el Ministerio de Salud y Protección Social generó lineamientos (8) y el Instituto Nacional de Salud (INS), los protocolos de manejo de las muestras (9). Sin embargo, el Ministerio, en la Circular 005 del 2020, determinó que la ruta de atención para la confirmación de casos sospechosos debía ser definida por la IPS, las Entidades Administradoras de Planes de Beneficio (EAPB) en conjunto con los entes territoriales siguiendo los protocolos de toma de muestras dados por el INS (8). Acompañando estas indicaciones, por ejem- plo, la Sociedad de Cirugía de Bogotá Hospital San José, en su protocolo de Manejo Institucional, estableció que "las muestras serán tomadas inicialmente por el personal de terapia respiratoria y según la demanda por otro profesional de la salud con entrenamiento" (10).

Por lo tanto, a continuación, presentamos los protocolos de recolección de muestras respiratorias de orofaringe y nasofaringe recomendados. Con esto contribuiremos a mejorar la calidad de la muestra para impactar directamente en el diagnóstico y manejo de pacientes con COVID-19.

\section{Preparación y equipamiento}

El equipo de protección personal (EPP) incluye gorro desechable, mascarilla de alta eficiencia (N95), pantalla facial (careta), gafas de succión, traje entero en material antifluido, doble guante desechable, bata en material antifluido y polainas $(9,10)$. Antes de comenzar el procedimiento, etiquete los tubos de muestra y complete los formatos solicitados (10). Si es posible, debe ponerse y quitarse el EPP en presencia de un observador que asegure el procedimiento (8-11).

Absténgase de tener objetos personales (joyas, anillos, etc.), colóquese el traje entero y las polainas, pase al área limpia en la entrada de la unidad de aislamiento. Revise visualmente que todos los componentes EPP son correctos. Lávese las manos con agua y jabón (o solución a base de alcohol), pónga- 
se un par de guantes, la bata, gorro, máscara protectora N95, gafas, careta y el otro par de guantes sobre el puño de la bata (12).

Figura 1. Equipo de Protección Personal. Se muestra la bacterióloga usando el EPP requerido durante la recolección de una muestra de hisopado nasofaríngeo.

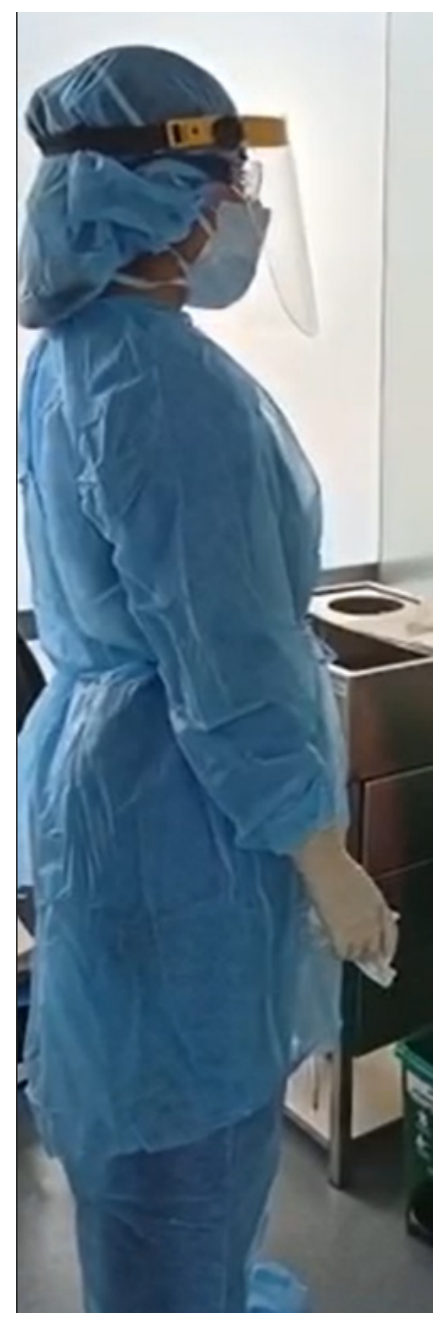

Fuente: Autores

\section{Procedimientos toma de hisopados}

Utilice hisopos de fibra sintética (poliéster) y mango plástico. No use hisopos de alginato de calcio o hisopos con ejes de madera, ya que pueden contener sustancias que inactivan virus e inhiben pruebas de PCR (9).
El hisopo nasofaríngeo es recomendado para el diagnóstico de COVID-19 en adultos y niños $(7,11,13)$. Si toma hisopos nasofaríngeo y orofaríngeo, combine en un solo tubo para aumentar la sensibilidad de la prueba (7).

Pídale al paciente que se quite la máscara y se suene la nariz con un pańuelo para eliminar el exceso de secreciones. Retire el hisopo del empaque. Incline la cabeza del paciente hacia atrás, en ángulo de $45^{\circ}$, así los conductos nasales son más accesibles. Pídale al paciente que cierre los ojos para disminuir la leve molestia del procedimiento.

Hisopo nasofaríngeo: inserte el hisopo a través de la fosa nasal paralela al paladar (no hacia arriba) hasta que encuentre resistencia o la distancia sea equivalente a la del oído a la fosa nasal del paciente, lo que indica contacto con la nasofaringe. El hisopo debe alcanzar una profundidad igual a la distancia desde las fosas nasales hasta la abertura externa de la oreja. Frote y gire suavemente el hisopo varios segundos para absorber las secreciones. Retire lentamente el hisopo mientras lo gira. Si hay tabique bloqueado o desviado, use el mismo hisopo para obtener muestra de la otra fosa nasal (7). Complemente con el video disponible. 
Figura 2. Obtención de hisopo nasofaríngeo.

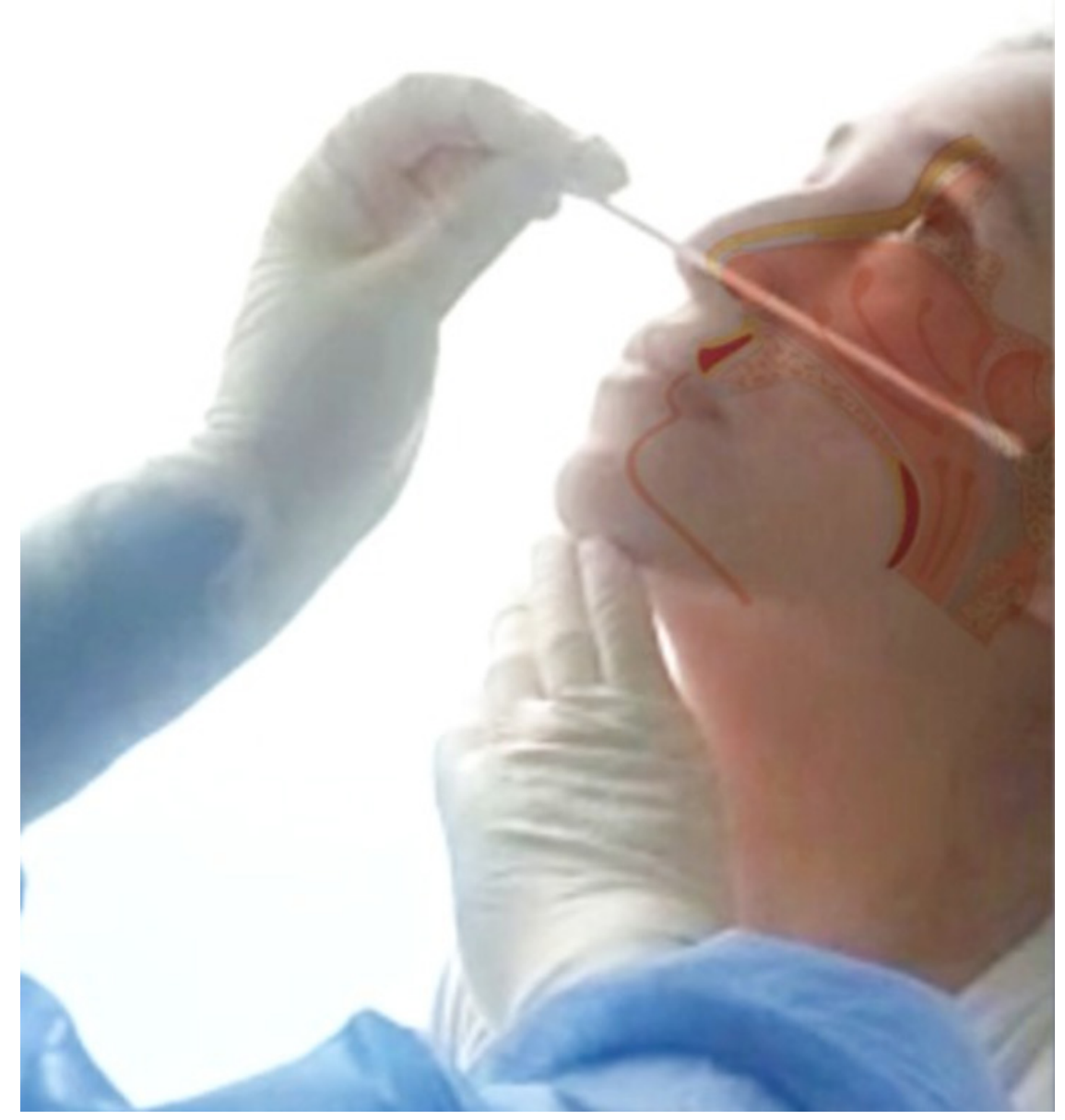

Fuente: Autores

Hisopo orofaríngeo: con la ayuda de un bajalenguas presione la lengua. Inserte el hisopo en la faringe posterior y el área de las amígdalas. Frote el hisopo sobre los pilares amigdalinos y orofaringe posterior. No tocar lengua, dientes y encías $(9,14)$.

El hisopo se introduce en el tubo que contiene $1,5 \mathrm{~mL}$ de medio de transporte viral, se rompe el mango del hisopo y se cierra el tubo. En caso de tomar los dos tipos de muestra, ambos hisopos deben colocarse en el mismo tubo de transporte viral (9).

\section{Almacenamiento de las muestras}

Almacene las muestras a $2-8^{\circ} \mathrm{C}$ hasta 72 horas después de la recolección. Si se espera un retraso en las pruebas o el envío, almacene las muestras a $-70^{\circ} \mathrm{C}$ o menos, evitar la congelación y descongelación repetida de las muestras $(7,9)$. 


\section{Embalaje/envasado y envío de las muestras}

El embalaje de las muestras debe constar del recipiente principal hermético que contiene la muestra (hisopo en el medio de transporte), el embalaje secundario hermético impermeable que protege el recipiente primario y el embalaje exterior o terciario rígido que protege al empaque secundario mientras está en tránsito (15).

\section{Retirar el equipo de protección personal}

Retire bata y guantes, lávese las manos con agua y jabón. Póngase un nuevo par de guantes y retire la careta facial, límpiela y guárdela. Quítese los guantes, vuelva a lavarse las manos y póngase otro par de guantes; luego quítese la mascarilla N95 y siga las pautas institucionales para su eliminación. Finalmente, quítese el último par de guantes y lávese las manos.

\section{Recomendaciones}

Tenga en cuenta la anatomía de la cavidad nasal para evitar la incomodidad del paciente y aumentar el rendimiento diagnóstico de COVID-19.

Asegúrese de tomar una muestra con alta calidad que asegure una cantidad significativa de ARN viral en la muestra.

\section{Referencias}

1. Lippi G, Simundic AM, Plebani M. Potential preanalytical and analytical vulnerabilities in the laboratory diagnosis of coronavirus disease 2019 (COVID-19). Clinical chemistry and laboratory medicine. 2020.

2. De Virgilio A, Pellini R, Mercante G, Ferreli F, Petruzzi G, Spriano G. Who should perform the rhinopharyngeal swab in COVID-19 positive patients? Head \& neck. 2020;42(6):1250-1.

3. Loeffelholz MJ, Tang YW. Laboratory diagnosis of emerging human coronavirus infections - the state of the art. Emerging microbes \& infections. 2020;9(1):747-56.

4. Mawaddah A, Gendeh HS, Lum SG, Marina MB. Upper respiratory tract sampling in COVID-19. The Malaysian journal of pathology. 2020;42(1):2335.

5. etruzzi G, De Virgilio A, Pichi B, Mazzola F, Zocchi J, Mercante G, et al. COVID-19: Nasal and oropharyngeal swab. Head \& neck. 2020;42(6):1303-4.

6. World Health O. Guidance for laboratories shipping specimens to $\mathrm{WHO}$ reference laboratories that provide confirmatory testing for COVID-19 virus: interim guidance, 2 March 2020. Geneva: World Health Organization, 2020 2020. Report No.: Contract No.: WHO/COVID-19/laboratory shipment/2020.2.

7. CDC. Pautas provisionales para la recolección, manipulación y análisis de muestras clínicas para $\mathrm{CO}$ VID-19. In: Prevention CfDC, editor. USA2020.

8. MinSalud. Lineamientos para la gestión de muestras durante la pandemia de SARS-CoV-2 (COVID-19) en Colombia. In: Social MdSyP, editor. Bogotá: Ministerio de Salud y Protección Social; 2020.

9. INS. Lineamiento para la vigilancia por Laboratorio de virus respiratorios. In: Salud INd, editor. Bogotá2020. 
10. Jimenez A. PROTOCOLO DE MANEJO INSTITUCIONAL PARA EL SINDROME RESPIRATORIO AGUDO SECUNDARIO A COVID-19. Sociedad de Cirugia de Bogotá Hospital de San José, 202025 Mayo 2020. Report No.: Contract No.: VERSION 11.

11. Marty FM, Chen K, Verrill KA. How to Obtain a Nasopharyngeal Swab Specimen. The New England journal of medicine. 2020;382(22):e76.

12. WHO. Steps to put on personal protective equipment (PPE) including gown. In: Organization WH, editor. 2015.

13. Wang QX, Zeng XH, Zheng SL. The nucleic acid test of induced sputum should be used for estimation of patients cure with 2019-nCov. European review for medical and pharmacological sciences. 2020;24(7):3437.

14. INS. Vigilancia por Laboratorio de Influenza y otros Virus Respiratorios en el Marco del Plan Antipandemia. In: Salud MdIPSINd, editor. 2007.

15. INS. GUÍA PARA LA VIGILANCIA POR LABORATORIO DE Bordetella pertussis. Instituto Nacional de Salud; 2017. p. 22. 